\title{
CONTAR SEGUIDO, ALINHAVADO, SÓ MESMO SENDO AS COISAS DE RASA IMPORTÂNCIA - SOBRE RETRATO, BIOGRAFIA E CONFISSÕES
}

\author{
Report in a followed, basting in line, is just for the things of shallow importance \\ - on portrait, biography and confessions
}

Contar seguido, hilvanado, solo si es cosa de rasa importancia - sobre retrato, biografía y confesiones

Gabriela Reinaldo

Professora da Universidade Federal do Ceará gabriela.reinaldo@gmail.com

\section{Resumo}

Segundo Iuri Lotman, o retrato é o mais filosófico dos gêneros pictóricos. O que fundamenta sua tese? Quanto mais aparentemente simples uma imagem, diz ele, mais complexas são as leituras que podemos tecer sobre elas. Nesse ensaio, nosso intuito é, partindo dos estudos de pesquisadores da imagem e do retrato, como Iuri Lotman e de Hans Belting, e da biografia, como P. Bourdieu, Giovanni Levi e outros, discutir a parelha palavra e imagem de modo a discorrer sobre as analogias entre o retrato e as narrativas de vida, biográficas ou confessionais. Além de unidos pelos vínculos problemáticos da mimese e da iconicidade sígnica, o retrato e a biografia fundamentam e constituem a noção de sujeito que surge com a Modernidade.

Palavras-chave: Retrato. Biografia. Imagem.

\begin{abstract}
According to Yuri Lotman, the picture is the most philosophical of pictorial genres. What supports his thesis? The simpler an image apparently is, he says, the more complex are the interpretations that we can weave about it. In this paper, our aim is to discuss the pair word and image in order to bring to light the similarities between the portraits and the narratives of life, being them biographical or confessional in accordance to the studies of researchers who study the image and the picture, such as Yuri Lotman and Hans Belting, and biography researchers, as P. Bourdieu, Giovanni Levi and others. Besides being connected by the problematic bounds of mimesis and semiotic iconicity, the picture and the biography underlie and constitute the notion of subject that comes up with Modernity.
\end{abstract}

Keywords: Portrait. Biography. Image.

\section{Resumen}


Segundo Yuri Lotman, el retrato es el más filosófico de los géneros pictóricos. ¿Qué fundamenta su tesis? Cuanto más simple se parece una imagen, dice él, más complejas son las lecturas que podemos hacer a cerca de ella. En este ensayo, nuestra intención es, partiendo de los estudios de investigadores de la imagen y del retrato, como Yuri Lotman y Hans Belting, y de la biografía, como P. Bordieu, Giovani Levi y otros, discutir el dúo palabra e imagen de manera a discurrir sobre las analogías entre el retrato y las narrativas de vida, biográficas o confesionales. Además de estar reunidos por los vínculos problemáticos de la mímesis y de la iconicidad sígnica, el retrato y la biografía fundamentan y constituyen la noción de sujeto que surge con la Modernidad. Sujeto que depende de las representaciones y de los papeles que se le atribuyen.

Palabras clave: Retrato. Biografía. Imagen.

"A incerteza sobre si mesmo gera no ser humano a propensão a ver-se como outros e em imagem", diz Hans Belting (2007, p. 15). Recorto esse trecho de Antropologia da imagem que, embora não discorra sobre a biografia no contexto em que está inserido, aponta equivalências que nos interessam discutir aqui entre o retrato e a escrita biográfica. Não podemos mais, depois d’As Meninas de Velázquez (figura 1), apreciar inocentemente uma imagem sem que nos perguntemos quem está retratando e quem está sendo retratado e qual o papel do fruidor nessa mise-en-scène. Quando pintamos, filmamos ou fotografamos, quando compomos um personagem performaticamente atentos ao seu figurino e aos seus movimentos ou quando biografamos, o que de nós se transfere para obra escondido sob a aparência do outro? Entendemos que a escrita biográfica em vários aspectos se avizinha do retrato, gênero pictórico que se fundamenta na semelhança (retratar vem de retrahere, que quer dizer copiar), e que, mesmo em se tratando de signos com diferenças e com marcas que os singularizam e que não podem ser desprezadas, sendo um do registro da imagem e o outro pertencente ao domínio da palavra, retrato e biografia acabam atuando de maneira correspondente. 


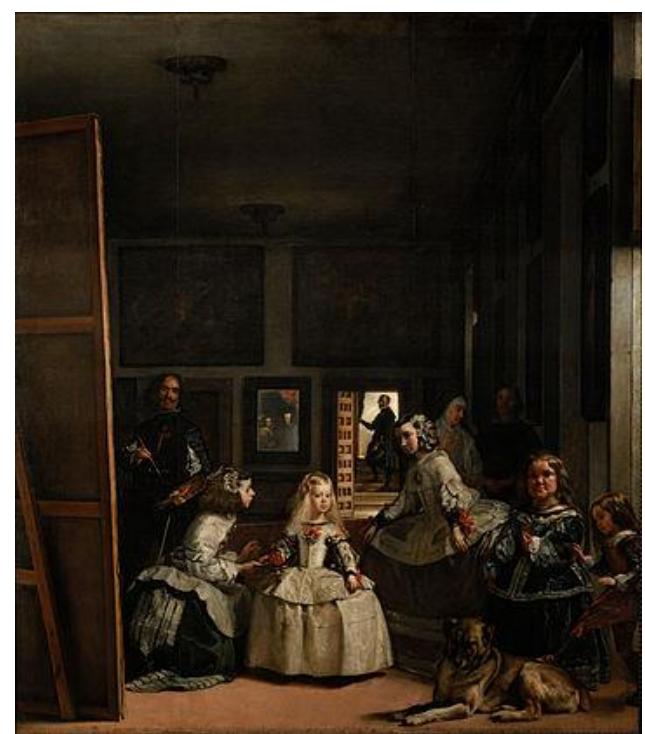

Figura 1 - VELÁZQUEZ, Diego. Las meninas. 1656. Óleo sobre tela, 3,18 x 2,76cm. Museu do Prado, Madrid.

Em “L'ecriture de soi”, Foucault diz que a escrita de si, caracterizada pela meditação e reflexão, é uma escrita ethopoética (a elaboração de um discurso sobre o eu é a própria forma de constituição desse eu). Ou seja, o eu nasce da escrita sobre si. No ocidente, diz Foucault, as Confissões de Agostinho, redigidas por volta do 400, inaugura o gênero autobiográfico como literatura filosófica da cura sui (cuidado de si). Antes dele, esboços de narrativas de vida podem ser encontrados de forma episódica em inscrições tumulares e, como lembra Georg Misch (Apud Galle e Olmos, 2007), na poesia de Propércio, Catulo e Ovídio, além dos escritos de Sêneca, Epicteto e Marco Aurélio.

Segundo a tradição, as crônicas das vidas de reis, faraós, sacerdotes e santos são narradas sem uma preocupação com a veracidade dos fatos, e sim como forma de enaltecer determinada figura, que deve ser admirada, imitada ou temida. Ensinamentos religiosos assentados sobre a narrativa de vida são encontrados nas três grandes matrizes das tradições religiosas contemporâneas: nos livros proféticos da Bíblia, nos ditos de Buda e Confúcio e, na literatura islâmica, dando continuidade à tradição muçulmana de contar a vida de sultões, califas, escritores e cientistas, não são poucas as passagens narrando a vida de Maomé.

Contudo, apenas na metade do século XVIII, com a ascensão do romance, a escrita autobiográfica conhece sua dimensão moderna. Confissões, só que desta vez de Jean-Jacques Rousseau, inaugura a nova face do gênero. A despeito do pensamento vigente na época, que duvidava da possibilidade de se escrever sobre a vida de um sujeito sem falseá-la, essa obra começa com a sentença: "Este é o único retrato de homem que existe e que provavelmente 
jamais existirá, pintado exatamente segundo o natural e em toda a sua verdade. " Rousseau, que não só acredita na possibilidade de se escrever sobre a vida do homem e - mais do que isso! - de fazê-lo sem distorções, é considerado, por Marshall Berman, uma personalidade fundamental na configuração da modernidade: "se existe uma voz moderna arquetípica antes das revoluções francesa e americana, essa é a voz de Jean-Jacques Rousseau" (BERMAN, 2007, p. 26). Não à toa, Rousseau é o primeiro a utilizar a palavra moderniste no sentido que será apreciada nos séculos XIX e XX. Ainda segundo Berman, Rousseau, figura mais modernista do que qualquer outra que tenha aparecido depois dele, é a matriz de algumas das mais vitais tradições modernas, como a auto-especulação psicanalítica e a democracia participativa. Se a modernidade é a contradição entre o desejo de mudança, de transformação do mundo e de si, e, ao mesmo tempo, o terror da desintegração e desorientação de viver num mundo em que tudo o que é sólido se desmancha no ar, Rousseau é a alma que animará esse projeto $^{1}$.

Contudo, outra voz insufla o nascimento da Modernidade. "Quand Dieu quittait lentement la place d'où Il avait dirigé l'univers et separé le bien du mal et donné un sens à chaque chose, don Quichotte sortit de sa maison et il ne fut plus en mesure de reconnâitre le monde ${ }^{2}$. Milan Kundera continua dizendo que o herói de Cervantes, “en absence du Juge suprême, apparut subitement dans une redoutable ambigüité ${ }^{3 "}$ (KUNDERA, 1986, p. 16-17) fazendo com que a verdade única e divina se decomponha em verdades relativas marcando não apenas o nascimento do romance ${ }^{4}$ mas fundando a sagesse de l'incertitude que é a marca dos tempos modernos. No que o acompanha Emma Bovary, Anna Karenina, Stephen Dedalus e tantos outros personagens que abandonaram o discurso dogmático e apodítico pelo da relatividade e ambiguidade.

Philippe Lejeune (1996), em Le pacte autobiographique, tratará mais detidamente das marcas de ficcionalidade, verdade e verossimilhança existentes na escrita biográfica. Segundo Lejeune, a diferença entre a escrita biográfica e a ficcional está nos pactos (contrat

\footnotetext{
${ }^{1}$ Berman diz que no século XX, o projeto modernista estará corrompido e se polarizará em movimentos que desembocam ou na excitação e compulsão de movimentos como o Futurismo - que rejeita todas as tradições colocando-as no mesmo saco e celebra a tecnologia a um extremo grotesco e autodestrutivo - ou na descrença que contamina toda a esquerda, como acontece com a escola de Frankfurt, que compreende as massas como desprovidas de senso crítico e capacidade de articulação e ação.

${ }^{2}$ Quando Deus deixou lentamente o lugar de onde ele dirigia o universo e separado o bem do mal e dado um sentido a cada coisa, D. Q. saiu de sua casa e já não era capaz de reconhecer o mundo.

${ }^{3} \mathrm{Na}$ ausência do Julgamento Supremo, (o mundo) apareceu subitamente uma temível ambigüidade.

${ }^{4}$ Segundo Kundera, Don Quijote de la Mancha inaugura o nascimento do romance. Há outros autores que consideram também Tristam Shandy, de Sterne (1713 - 1768), um dos primeiros romances. Em ambos os casos, as histórias e seus heróis evidenciam a complexidade do homem, seu caráter contraditório, fragmentado e em perpétua mutação.
} 
de lecture) que se estabelecem entre o autor e o leitor. Enquanto a realidade ficcional se apoia na verossimilhança, se convencionou ler uma biografia em termos de referencialidade: a lógica do texto ficcional é dada no próprio texto. Não dizemos que determinado livro de ficção é bom ou ruim de acordo com as verdades ou segundo as invenções que ele contém. Já a leitura de uma biografia é pautada pela verificação extratextual, pelas experiências colaterais do leitor, que buscará em outras fontes as informações que o deixará apaziguado ou não com o que leu. Podemos estender esse pensamento também para a imagem no retrato. A qualidade da obra será sempre apreciada de acordo com os pactos estabelecidos. Nesse sentido, avaliar um retrato positivamente equivale a dizer que ele é "fiel" ao retratado, que ele correspondente ao que se "vê" ou ao que se imagina do sujeito reproduzido levando-se em conta os traços de sua personalidade ou de sua fisionomia.

À pergunta "é possível contar a vida de alguém? " Bourdieu responde que falar da história de vida é pressupor que a vida é uma história (BOURDIEU,1998, p. 183). Ou seja, um percurso que se desenrola unidirecional e linearmente (esse conceito de história prevaleceu durante muito tempo, deixando marcas que são difíceis de apagar) tendo como início o nascimento do sujeito e como desfecho a sua morte. Assim, a narrativa desse percurso "coerente" e "orientado" vincula-se à crença na existência de um sentido para a vida. É de se notar que a palavra sens (sentido), no francês que escreve Bourdieu (e também no português sentido e em outras línguas latinas) é um significante com a duplicidade semântica que abriga os significados "vetor de direção" - portanto sentido como direção e orientação - e capacidade de ajuizamento sobre o que algo significa. A busca de um sentido para a vida, proposta pela biografia, não passa de uma ilusão retórica, diz Bourdieu, uma representação sustentada por toda uma tradição literária que se alicerça em uma lógica causal e a reforça.

Não é de espantar, portanto, que o surgimento dos novos paradigmas na Física que deram origem à crise da concepção mecanicista e o aparecimento da Psicanálise - que credencia a existência de um Mister Hide que se esconde (como indica o sobrenome Hide) na pele do pacífico Dr. Jekill (Robert Louis Stevenson publica seu romance em 1886, quatro anos depois do recém formado S. Freud começar suas pesquisas com pacientes com sintomas clínicos neuróticos e histéricos) -, coincida com a nova escrita literária, que borra os limites entre o real e do ficcional, reconhecendo a importância do ponto de vista do observador e a existência de um outro, que vive em nós mesmos, como se pode perceber nos stream of consciouness joyceanos. O sentido, agora, já não obedece a uma orientação cronológica Riobaldo, herói de Grande sertão: veredas, em sua autobiografia fictícia, avisa: "contar 
seguido, alinhavado, só mesmo sendo as coisas de rasa importância” (ROSA, 1978, p.78) nem a uma determinação lógica externa ao sujeito. O romance nasce da descoberta de que o real é descontínuo e aleatório. A noção de indivíduo, de pessoa única, que surge com a modernidade e fertiliza o terreno da biografia e do retrato, valorizando-os e fazendo com que se proliferem nas esferas política, ritualística e sacra e na mundana, é redimensionada. A identidade do sujeito, agora abalada, torna-se mais complexa, e, hoje, as contradições da vida dos protagonistas, que na imagem corresponderiam às assimetrias e às sombras, são mais valorizadas.

São essas questões, sempre tensas, que acreditamos aproximar a escrita biográfica do retrato. Ambos têm nascimento incerto, ligado ao culto religioso ou mágico; constituem-se, tal como os conhecemos hoje, na Modernidade - com todas as suas marcas de indefinição e complexidade - e transitam no terreno sinuoso do signo que quer se confundir e tomar o lugar do seu objeto.

A palavra retrato vem, como dissemos anteriormente, de retrahere, que no latim quer dizer "copiar", e sua função primeira não era representar o retratado, testemunhar sua existência, mas magicamente substituí-lo. No antigo Egito, o retrato servia para que o morto pudesse ser reconhecido quando chegasse do lado de lá. Desse modo, o retrato tem os mesmos atributos que o Nome Próprio, a dupla função de identificação jurídica e também mística, diz Lotman (2000). Assenhorar-se do nome ou da imagem de alguém é, para o pensamento arcaico, tomar o lugar desse alguém e reivindicar seus poderes. No retrato, mesmo o atual, essa dimensão mágica e evocativa não se desgasta. Se João Paulo II ou Bento XVI aparecem pendurados nas paredes das casas de famílias cristãs com o propósito de abençoá-las, os retratos do Führer cobriam os muros da Alemanha nazista e dos países conquistados não apenas para representar o comandante do país. Deste modo, Hitler poderia estar presente no cotidiano das pessoas, observando seus comportamentos e perscrutando o mais íntimo de seus espíritos. 


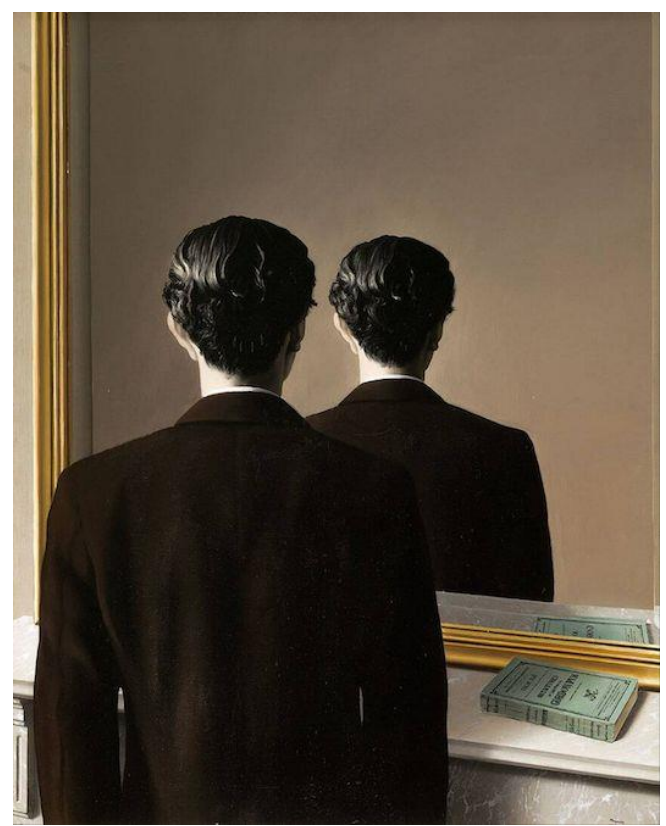

Figura 2 - MAGRITTE, René. La réproduction interdite, 1937. Óleo sobre tela, 81 x $65 \mathrm{~cm}$. Museu Bojimans Van Beuningen. Rotterdam.

A partir das revoluções da arte moderna, no começo do século XX, a mimese, no sentido de imitação, torna-se um conceito obsoleto para as artes (BAYER, 1978; GEBAUER \& WULF, 2004). Em La réproduction interdite (figura 2), Magritte cria um espelho que não obedece às leis da Física. E embora atualmente haja um desprezo pela imitação (mesmo que essa tenha sido revisitada e revalorizada com Auerbach na década de 1980), ainda hoje o retrato se afirma como gênero pictórico por sua semelhança com o modelo vivo. Contudo, não existe uma "naturalidade" no que convencionamos achar parecido. A mimese, no retrato ou na biografia, se apoia em construções históricas, ideologias e convenções de gosto. Enxergamos algo como semelhante elegendo traços distintivos convencionados culturalmente. Na imagem, o que nos parece semelhante ou diferente é fruto de uma gramaticalidade que, em parte, é aprendida.

Culturalmente, a mimese está associada aos cultos e à magia simpática, que se afirma pela similaridade. Na literatura, há dois casos bastante significativos que tratam da iconicidade sígnica no retrato. Em The Picture of Dorian Gray, o jovem dândi está no esplendor de sua beleza e juventude quando é pintado por Basil Hallward. O herói de Oscar Wilde encarna o ideal grego - que tanto se debruçou sobre a mimese a partir de tradições por vezes contrárias no que tange a esse assunto, como o pensamento de Platão e Aristóteles corrompido. Se na obra de Wilde, o retrato está no centro de tramas macabras em que se 
urdem perversão, luxúria e vaidade, em Oval Portrait, de Edgar Alan Poe, publicado quase 50 anos antes, a monomania, paranoia que provoca obsessão por uma ideia fixa, faz com que um jovem pintor apaixonado pela esposa retire de sua seiva vital as tintas para compor o seu retrato. Nas últimas linhas, diz o texto: "And then the brush was given, and then the tint was placed; and, for one moment, the painter stood entranced before the work which he had wrought 5 ". E no momento final: "but in the next, while he yet gazed, he grew tremulous and very pallid, and aghast, and crying with a loud voice, 'This is indeed Life itself!' turned suddenly to regard his beloved: - She was dead!'”. Em ambos, a correspondência entre signo e objeto - "This is indeed life itself!" - é o que corrompe o real e leva à morte ${ }^{7}$

Nos atos miméticos, o homem não apenas copia: ele inventa o mundo. Interfere positivamente na sua configuração. Em outras palavras, a mimese não é um ato passivo, uma vez que existe uma escolha do que deve e do que não deve ser copiado. Quando uma criança imita os pais, ela aprende a falar, a andar, a comer, mas também a fazer isso de forma diferente do que fazem ou faziam os seus ancestrais. Desse modo, a mimese, ao mesmo tempo em que integra o sujeito ao social, é um exercício de singularidade. Quando o homem, observando a natureza, reproduz a forma ou os movimentos de um pássaro em forma de pintura, representação cênica ou escultura, ele acrescenta ao mundo existente algo que não estava lá. Ele atribui um sentido simbólico ao pássaro fabricado. O mesmo acontece nos retratos pintados por Guignard ou por Anita Malfatti. O retrato de Murilo Mendes ou de Mário de Andrade, pintados respectivamente por Guignard e por Malfatti, acrescentam algo à biografia desses poetas, misturando imagem e poesia. Há um quê de desconcertante no rosto pintado que reflete como Guignard ou Malfatti viam, fisiologicamente, Murilo Mendes ou Mário de Andrade. Pinceladas que revelam como os pintores os enxergavam subjetivamente integrando Macunaíma, Gilda ou Jandira às faces de seus idealizadores.

\footnotetext{
5 "E então, a pincelada foi dada e o tom aplicado e, por um instante, o pintor se deteve extasiado diante da obra em que trabalhara".

6 "Porém, em seguida, enquanto ainda a contemplava, ficou trêmulo, muito pálido e espantado e gritou alto: 'Isto é de fato a própria Vida!' Voltou-se repentinamente para olhar sua amada: - Ela estava morta!"

${ }^{7}$ Sublinhamos que, além dos livros acima citados, o uso dos termos Retrato, Picture ou Portrait que aparecem com frequencia em títulos de obra que pretendem contar de modo ficcional ou não a vida de alguém - como A portrait of the artist as a young man, de Joyce; Retrato em branco e negro, de Lília Schwarcz; Retrato do artista quando coisa, de Manoel de Barros ou Auto-retrato e outras crônicas de Carlos Drummond de Andrade - é significativo da relação entre retrato e narrativa de vida.
} 


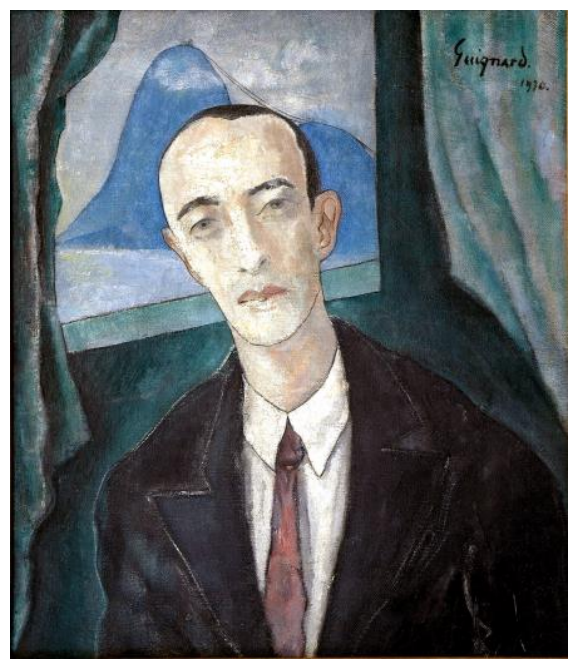

Figura 3 - GUIGNARD, Alberto da Veiga. Retrato de Murilo Mendes, 1930. Óleo sobre tela, 60,5 x 52 cm. Coleção Murilo Mendes.

A imitação, ao criar referencialidades, produz também zonas de conforto, de hábitos. E hábitos nada mais são do que a repetição ou cópia de gestos, formas de pensar e de se comportar que se constituem de modo a imprimir um sentido, uma coerência, uma ordenação para o caos dos fenômenos da vida. Narciso, como diz Caetano em Sampa, acha feio o que não é espelho, embora não haja quem sobreviva ao avesso do avesso do avesso do avesso. Contudo, como dissemos anteriormente, a atividade mimética não é apenas um ato apaziguador. Não há uma cópia perfeita. Quando imitamos algo ou alguém, nos relacionamos e constituímos vínculos e fazemos descobertas sobre o imitado - ato que tem consequências íntimas: uma porta se abre revelando-nos algo sobre nós mesmos.

Em sua autobiografia filosófica, intitulada Bodenlos, Vilém Flusser dedica todo um capítulo sobre 12 personalidades que tiveram importância para a sua vida. Escrevendo sobre a vida de outros, Flusser - que elege como título da narrativa de sua própria vida um termo alemão para dizer sem fundamento, sem chão - fala de si mesmo. As palavras sobre Alex Bloch, Guimarães Rosa, Dora Ferreira Guimarães, Haroldo de Campos, Samson Flexor, entre outros perfilados, são reveladoras de como Flusser os via, de como os sentia e, desse modo, são autorretratos do autor que conscientemente os assume como parte de sua autobiografia ${ }^{8}$.

\footnotetext{
${ }^{8}$ Sobre o tema, escrevi O retrato de Rosa em Bodenlos, publicado na Flusser Studies, n. 8 (http://www.flusserstudies.net/pag/08/reinaldo-rosa.pdf)
} 


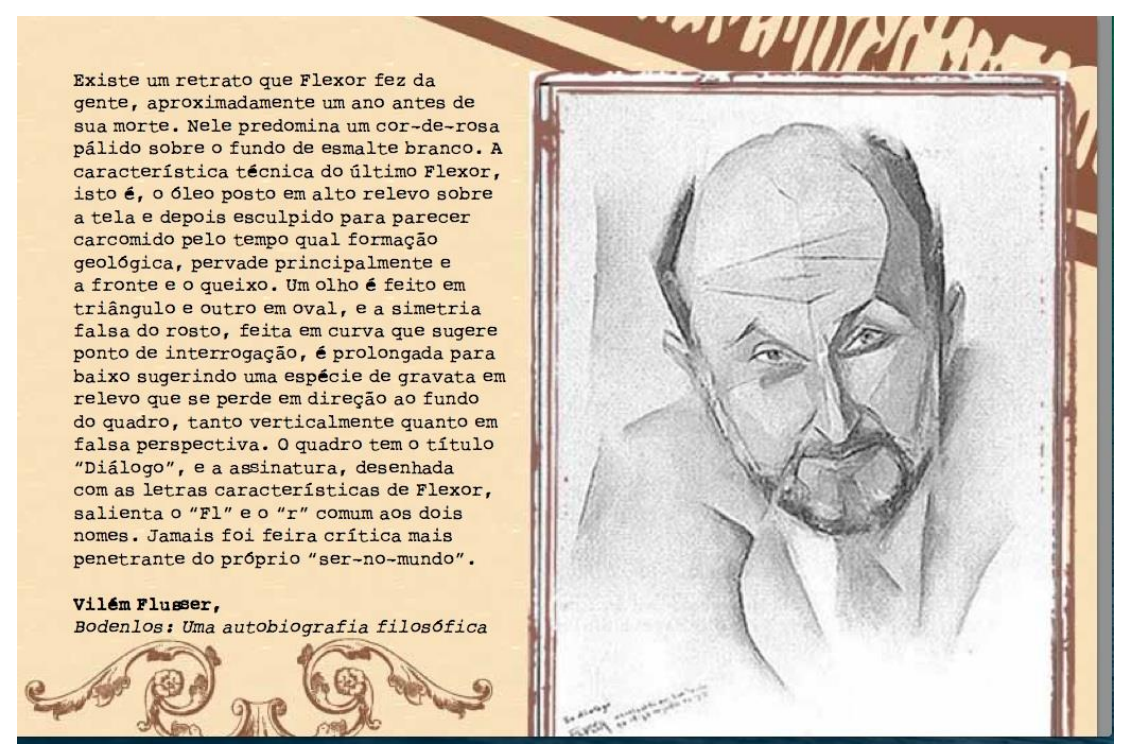

Figura 4 - Montagem da autora. Trecho de Bodenlos: uma autobiografia filosófica, de Vilém Flusser; e Vilém Flusser, pintura de Samson Flexor.

Do mesmo modo que quando representamos alguém, expomos a nós mesmos, também quando pintamos nosso autorretrato ou mesmo quando nos fotografamos ou nos filmamos, há aspectos nossos que são revelados. Aspectos que, embora existam de fato, não estão presentes (ou não são observados) no nosso rosto sem essa mediação. Nesse sentido, é bastante significativa a galeria pintada por Van Gogh (figura 5). Mesmo que nem todos os diferentes Van Goghs olhem para nós - embora na sua totalidade nenhum desvie o rosto para outro lado que não seja para o observador, o que colabora com a tese de que foram feitos diante de um espelho - a maioria deles têm os olhos atentos na direção do nosso olhar. E não são apenas os tons das cores, as paisagens ao fundo, o rosto ora mais jovem ora mais ossudo e anguloso, o corte do cabelo, o tipo de roupa que ele está usando ou as texturas das pinceladas que os fazem tão diferentes e tão iguais (uma vez que se trata do mesmo sujeito) entre si. Há Van Goghs sobre um fundo quase fauvista, intensamente laranja ou verde - cores do Taiti e da Martinica de seu conviva Paul Gauguin ${ }^{9}$, para quem dedica a imagem -, há os que se perdem em sombras e há também um rosto de aspecto tão luminoso que parece espectral, sugerindo uma luz abaixo da pele.

\footnotetext{
${ }^{9}$ Vale lembrar que o autorretrato dedicado a Gauguin é de 1888, logo que o pintor abandona os Arles, onde viveu e pintou com Van Gogh, e a arte impressionista. Em 1889, Gauguin viaja para ilha caribenha com a intenção de retomar a vida que levava no Taiti.
} 


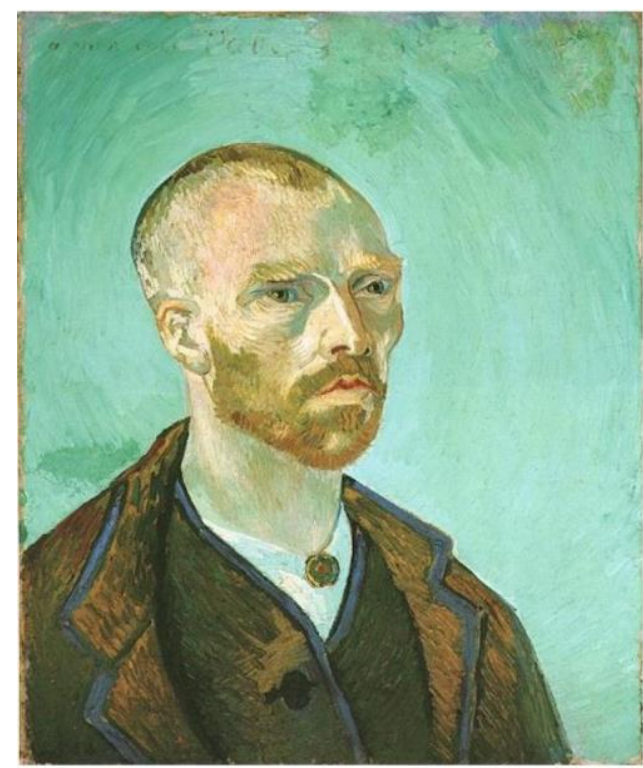

Figura 5 - GOGH, Vincent van. Autorretrato (Dedicado a Paul Gauguin). 1888. Óleo sobre tela, 62 x $52 \mathrm{~cm}$. Cambridge (MA), Fogg Arts Museum.

A prática do autorretrato também pode servir na composição de um personagem com quem o pintor se identifique e que tenha correspondências com o estado de ânimo de determinado momento de sua vida. Assim, o transgressivo e impetuoso Baco, no auge de sua beleza e juventude, é Caravaggio. Também a cabeça de Golias, com mostras de uma morte agonizante na mão de Davi, é um autorretrato do pintor, que se via, naquele momento, não no papel do herói bíblico, mas no do gigante humilhado e vencido (figura 6).

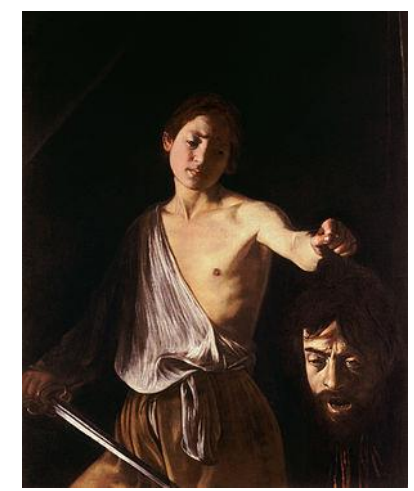

Figura 6 - CARAVAGGIO. Davi com a cabeça de Golias. 1610. Óleo sobre tela, 125 x 100 cm. Galleria Borghese.

O conceito de retrato mais corrente nos dicionários vernaculares e mesmo nos livros especializados em História da Arte diz que o gênero se trata de uma representação elaborada a 
partir da imitação ou cópia de uma pessoa viva. Entretanto, dizer que o retrato é um gênero pictórico que se caracteriza pela semelhança, é, segundo Hans Belting, uma conceituação simplificadora e equivocada. Para Belting, é preciso ter em conta que o conceito de semelhança é incerto e que nem sempre ele disse respeito ao que hoje, depois do advento da fotografia, consideramos semelhante em termos de imagem. Além disso, Belting (2007, p. 43), que sustenta a tese de que a análise de uma imagem não pode desprezar a mídia (corpo) que a suporta, afirma que não é correto comparar imagens de pessoas inscritas em pinturas, afrescos, murais ou em tábuas de madeira portáteis: "só se pode falar de um retrato autônomo quando este se converte em seu próprio tema e aparece em um meio próprio, neste caso transportável, do qual recebe seu caráter formalmente e no que diz respeito ao seu conteúdo". Nesse sentido, podemos extrair mais conclusões acerca do retrato se o compararmos com os escudos de armas - uma vez que retratos e escudos compartilham o mesmo suporte que são as tábuas de madeira - do que com outras imagens de pessoas.

De acordo com Belting, os pintores de escudos e de retratos são os mesmos e há pontos coincidentes entre eles, embora devido às singularidades de seus usos, rivalizem seus sentidos. No escudo, ao contrário do retrato, não há a representação de uma pessoa, e sim a de uma genealogia familiar ou territorial. A heráldica produzia pessoas jurídicas que suplantava às físicas, ao passo que, no retrato, se preza a duplicação fisionômica de um indivíduo, fazendo dele o portador vivo de um corpo que é mortal. E embora retrato e escudo sejam meios do corpo, no sentido de substituírem-no, estendendo sua presença no tempo e no espaço, o rosto que aparece no brasão não é o rosto de alguém, mas uma imagem dinástica, genealógica. Entre o corpo efêmero e mortal de quem o porta e o espectador, o escudo oculta o rosto verdadeiro. Ele é o rosto oficial, legitimador dos direitos do portador, diz Belting. Ligados à prática da guerra, vinculam o corpo a um signo de sua classe social ou categoria. Embora sejam diferentes, em suas histórias há muitos pontos coincidentes. Como não eram considerados obras de arte, muitos escudos não foram colecionados e devidamente armazenados e perderam-se. Os poucos que restam estão com frequência ligados ao retrato. Dípticos e trípticos têm, em seus versos, imagens de escudos que foram incorporados como abas ou como cobertas que protegiam os quadros durante as viagens. Se escudos e retratos se aludiam mutuamente, testemunhando a existência de uma pessoa - coletiva, familiar, heráldica no caso dos escudos; ou como representação de um corpo natural da pessoa viva, para o que se presta o retrato - as suas diferenças se acentuaram com o tempo e as 
semelhanças se excluíram devido "à pressão da competência burguesa, do humanismo e de um conceito de pessoa distinto" (BELTING, 2007, p. 151).

É quando entra em cena a descrição do sujeito, de um eu interior e contraditório. Neste sentido, o retrato, como o conhecemos hoje, está firmemente urdido com a biografia. Só o descobrimento do sujeito moderno, que pode se narrar (autobiografia ou autorretrato) ou pode ser narrado por um outro, estabelece a distinção de papéis ${ }^{10}$. Esses novos papéis não pertencem mais nem a uma herança divina nem tampouco a uma genealogia aristocrática. Desejosos de serem reconhecidos pelos seus feitos (e não graças a uma linhagem), os humanistas são frequentemente representados com um livro na mão. E assim surge o retrato radicalmente fisionômico (e por que não dizer biográfico?), rompendo com a última instância dos retratos genealógicos, se apartando de vez dos escudos, concebendo um corpo individual como imagem.

Plasticamente é a nova frontalidade, garante Belting, que diferencia o retrato da figura heráldica com seus rígidos perfis. É o olhar dirigido ao espectador que separa de vez o retrato dos escudos. Por meio do olhar, surge o dualismo interior e exterior (BELTING, 2007) e se inaugura a metáfora do olho como janela da alma. É a descoberta do $e u$, um eu que quer falar de si e que, entretanto, precisa se descobrir como um $\mathrm{eu}$ - o que tem equivalências com o que Foucault, na escrita, chamou de função ethopoética.

Segundo Lotman, podemos dizer que a dinâmica da construção do retrato destaca traços da pessoa humana aos quais são atribuídos um sentido dominante em relação a outros, que são desprezados ou não reconhecidos como existentes (LOTMAN, 2000). Assim como na escrita biográfica, no retrato não se copia tudo do retratado - até por que acreditar que exista um "tudo", um objeto apartado do signo, corromperia a equação sígnica que tem matriz em Agostinho, quando ele diz que o mundo só é reconhecível através do signo, e que desemboca numa tradição de interpretação que, no pensamento peirceano, que urde firmemente signo, objeto e interpretante -, mas se elegem características que o tornam reconhecível. Dito isso é importante ter em conta a pergunta: que serventia teria o mapa se ele representasse toda a paisagem? Ou, como dizia Pirandello, a vida é tão absurda que para contá-la é preciso uma dose de ficção para que ela seja aceita como real. Tanto no retrato quanto na escrita biográfica, as pessoas são transformadas em personagens para que suas vidas possam ser narradas.

\footnotetext{
${ }^{10}$ Juntamente com o surgimento do retrato, duas figuras começam a ser representadas. O crânio, rosto anônimo da morte, aparece confrontado com o rosto vivo do retrato. Além do crânio, a máscara é retratada como representação dos papéis que desempenhamos. Sobre o tema ver Antropologia da Imagem, de Hans Belting.
} 
Transformar em personagem uma pessoa não significa despojá-la de suas contradições. Exaltar apenas alguns traços em detrimento de outros, pode criar uma caricatura. O que constitui a personagem são as situações enunciativas em que ela se encontra. Anatol Rosenfeld diz que as personagens têm um cunho mais definitivo e também mais definido do que podemos perceber no convívio com pessoas reais, complexas, caleidoscópicas e que têm suas vidas desenroladas numa sucessão de acontecimentos impossível de ser narrada. Ficcionalizadas, tornam-se mais nítidas. Para conhecer o real, o recriamos. Os caminhos da verdade do ser passam pelo delírio da imaginação. Transformadas em personagens, as pessoas tornam-se mais coerentes, exemplares e, paradoxalmente, mais ricas. "Não por que sejam mais ricas do que as pessoas reais, e sim em virtude da concentração, seleção, densidade e estilização do contexto imaginário, que reúne os fios esfarrapados e dispersos da realidade num padrão firme e consistente" (ROSENFELD, 2007, p. 35). A personagem está ligada à atividade performativa e mimética. Aristóteles ensina em sua Poética que personagem, que vem de persona, máscara, é aquele que imita, imita uma ação, que pode ser boa ou má.

Máscara assumidamente exercida na pose. O avanço das técnicas de fotografia corresponde ao avanço da produção de imagens acidentais e das que podem ser feitas sem o consentimento do retratado. Podemos dizer que o que liga os retratos atuais a toda uma tradição retratística - de Jan van Eyck (figura 7), na arte flamenca, a Piero della Francesca ou Domenico Guirlandaio, na Itália - é a pose. Na pose, o corpo se ajusta ao modo como o sujeito se vê e como ele quer ser visto. Afetada ou calculadamente despojada, a pose coloca o retratado frente a frente com seus ideais estéticos, com seus costumes, seus valores e com a sua satisfação ou insatisfação com sua própria aparência. Aquele que posa para um quadro de um pintor se oferece ao espetáculo da contemplação voyeurista e tem sua performance gestual calculada. 


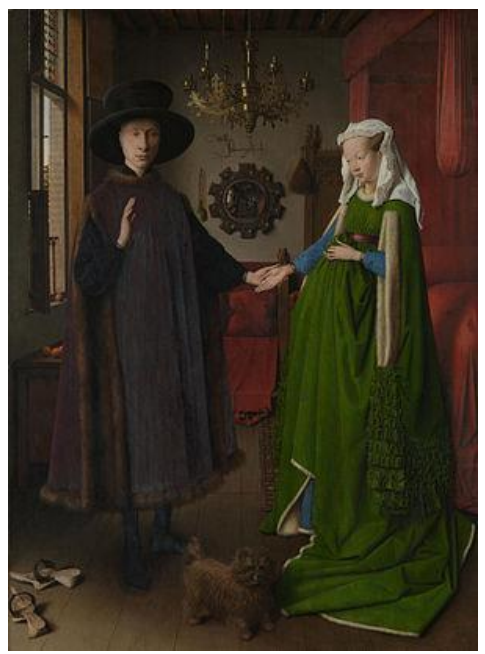

Figura 7 - EYCK, Jan van. O casal Arnolfini, 1434. Óleo sobre tela, 82 x 60 cm. National Gallery, Londres.

Na pose, o pouso e a pausa. A suspensão de um movimento que não deve ser confundida com imobilidade. No caso de uma pessoa, não se poderia desvinculá-la de sua gestualidade. Daí por que os bonecos de cera, para atrair nossa empatia, estão sempre em poses que descrevemos no gerúndio: cantando, olhando, beijando, falando, tocando, dançando, sorrindo. Não há interesse por um títere com os cordéis largados no chão. A rigidez nos remete à morte, e o retrato, sendo virtualidade, é tentativa de vencê-la. É a ausência ou presença deste movimento - que na escrita corresponderia ao verbo - no que está em princípio imóvel, imagem estática, que faz com que um retrato seja ou não revelador por que a revelação que interessa ao retrato é a do estado de alma, do que anima.

E falar de pose, pose que anima, é lembrar-se de Luís XIV, com suas fartas perucas e sapatos com saltinhos. Retrato e biografia estão juntos na corte absolutista e têm um papel importante na legitimação política do rei. No subcapítulo Mimese como instrumento de Poder, do livro Mimese na Cultura, Gebauer e Wulf dizem que a representação - pictórica ou textual - do rei era mais importante do que as aparições de Luis XIV em pessoa. Juntam-se aos biógrafos e historiógrafos, os pintores e arquitetos de palácio e jardim, que são autorizados a "participar, na área dos símbolos e das fantasias, como parte de uma imensa máquina de representação e interpretação, na construção e formação do poder político" (2004, p. 31). Também nessa época, a mimese participa na formação do "bom gosto" e dos "sentimentos nobres" (que tinham origem na corte e em mais nenhum lugar) que serão apreciados também quando a burguesia se instala no poder. 


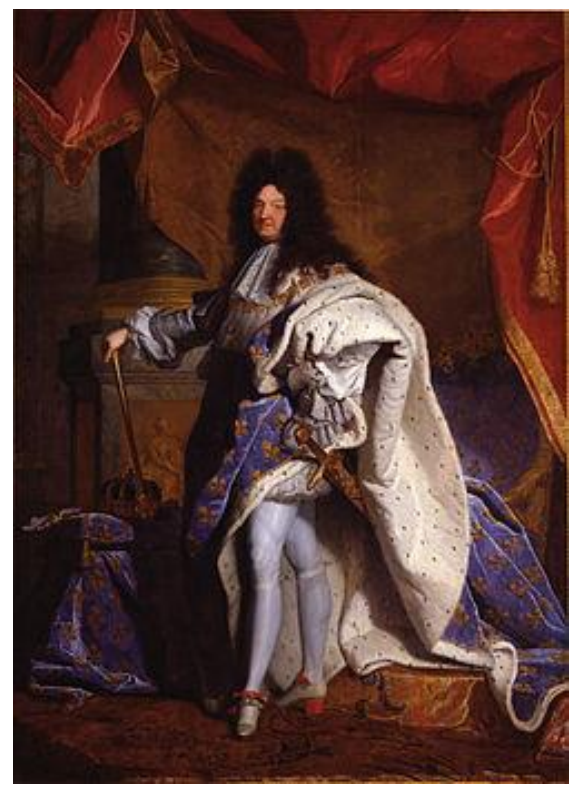

Figura 8 - RIGAUD, Hyacinthe. Louis XIV en costume de sacre. 1701. Óleo sobre tela, 277 x $194 \mathrm{~cm}$. Musée du Louvre, Paris.

Em O Burguês Ridículo, de Molière, a nova classe em ascensão, com dinheiro (e sem estirpe!), é ludibriada por um bando nobres falidos e mal-intencionados, e ecoa de forma absolutamente atual. Voltando à corte absolutista (ver figura 8, obra de Hyacinthe Rigaud que imortalizou a imagem de Luís XIV), é lá que surge a ficcionalização universal da História e de seus atores. Neste período, é criada uma escrita e uma arte pictórica performativa que tem a intenção de provocar maravilhamento no espectador. E assim,

todas as diferenciações entre acontecimento, discurso, imagem e escrita devem ser superados: o escrito deve tornar-se vivo tanto no leitor quanto em um discurso; o texto deve agir de forma imagética; o quadro deve alcançar a substância da história; o texto escrito deve permitir que a substância se mostre (...) O legível torna visível, e o visível é legível. (GEBAUER \& WULF, 2004, p. 32).

Também o retrato pintado, tradição ainda viva no sertão do Nordeste do Brasil, está intimamente ligado a uma narrativa biográfica, algumas vezes fantasiosa, comprometida com a idealização da vida do retratado. O que nasce ali vem de uma relação entre o fotógrafopintor e o objeto de sua imagem e quanto mais verdadeiro o encontro, maior o sucesso da empreita. Um photoshop quente, sensível aos desejos da alma, às fantasias e aos gostos. Nas mãos do artesão que pinta a fotografia, a moça que não casou ganha véu e grinalda, o defunto que não tem registro vivo abre os olhos, o careca ganha farta cabeleira e têm dentes de ouro e 
paletó de seda com brilho aquele que labuta na roça. É a pretensão da objetividade fria da fotografia transformada em sonho, alterando o estatuto da vivido de acordo com o desejo do retratado. Nesse mesmo cenário, em que o pastel e o óleo reinventam o resultado da fotografia, o cordel desacata o discurso oficial do jornal e da academia biografando personagens que se revelam, graças à força da oralidade e das imagens impressas na capa, santos ou heróis, como Padre Cícero ou Lampião.

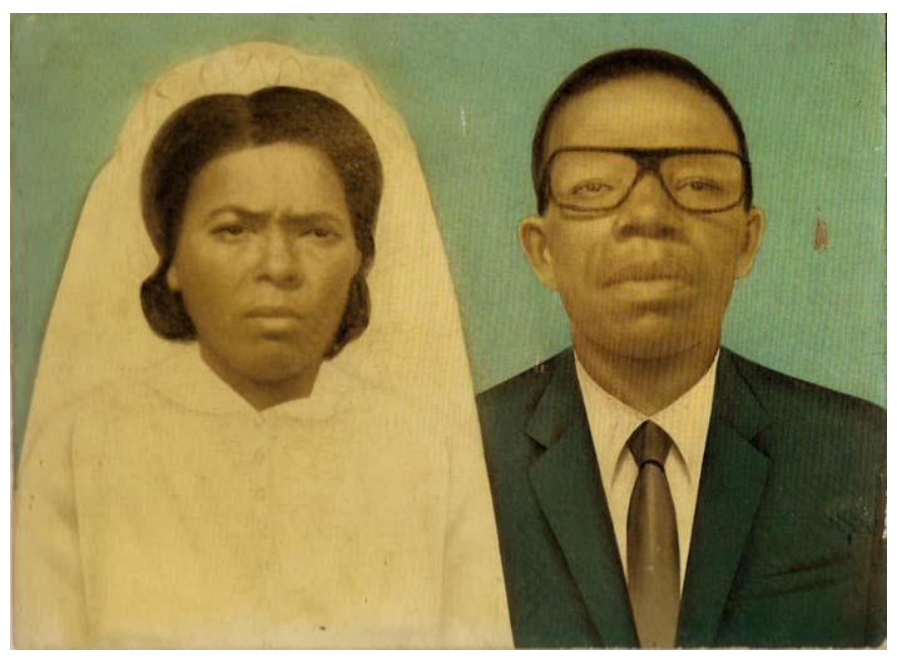

Figura 9 - Retrato pintado, NE brasileiro. Arquivo de Titus Riedl.

Nesse tipo de representação, biografia ou retrato, o que não aparece é tão ou mais revelador do que o que é mostrado. E o fruidor atento percebe que a inesgotabilidade da obra - sejam elas as Confissões de Rousseau ou a Mona Lisa de da Vinci - se deve às suas sombras e sobras, ao que ultrapassou o limite da moldura e do ponto final, às zonas obscuras situadas entre o dito e o não dito, ao que não está posto, mas em mudança, às possibilidades não necessariamente realizadas.

Tão misterioso quanto o que esvai para além da moldura é o que é por ela balizado. São as sombras que contornam os personagens, escondendo alguns de seus traços ou a paisagem ao fundo e acolhendo-os como mantos protetores. Efeitos que são cultivados no tenebrismo que radicaliza o chiaroscuro barroco, num jogo de esconde e revela; sombras como fendas e entreditos que aparecem nas fotos de Diane Arbus feitas com flashes em plena luz do dia, numa atitude anti-barroca, anti-teatralidade, anti-suntuosidade.

Podemos intuir, cientes que somos da biografia de João Batista, para quem ou para o quê aponta o dedo do santo no quadro de da Vinci. Contudo, saber para onde se dirige o olhar melancólico de Cecília, que tem ao colo um arminho (figura 10), pintado pelo mesmo 
Leonardo, solicita mais da nossa imaginação. Costumamos completar a Gestalt do que lemos ou vimos com as nossas próprias vivências, de acordo com o nosso tempo e com os nossos valores e o fazemos guiados pelas marcas que o autor deixou na obra, nas zonas obscuras e indeterminadas e ao mesmo tempo perfeitamente calibradas - mesmo que na imagem ou na escritura nem todo ajuste seja resultado de um ato consciente de criação. Ultrapassamos a obra e não nos damos conta de que fomos conduzidos por ela à nossa própria interioridade, que não sabe mais separar o que é nosso do que é do retratado ou do biografado e do que é do próprio autor.

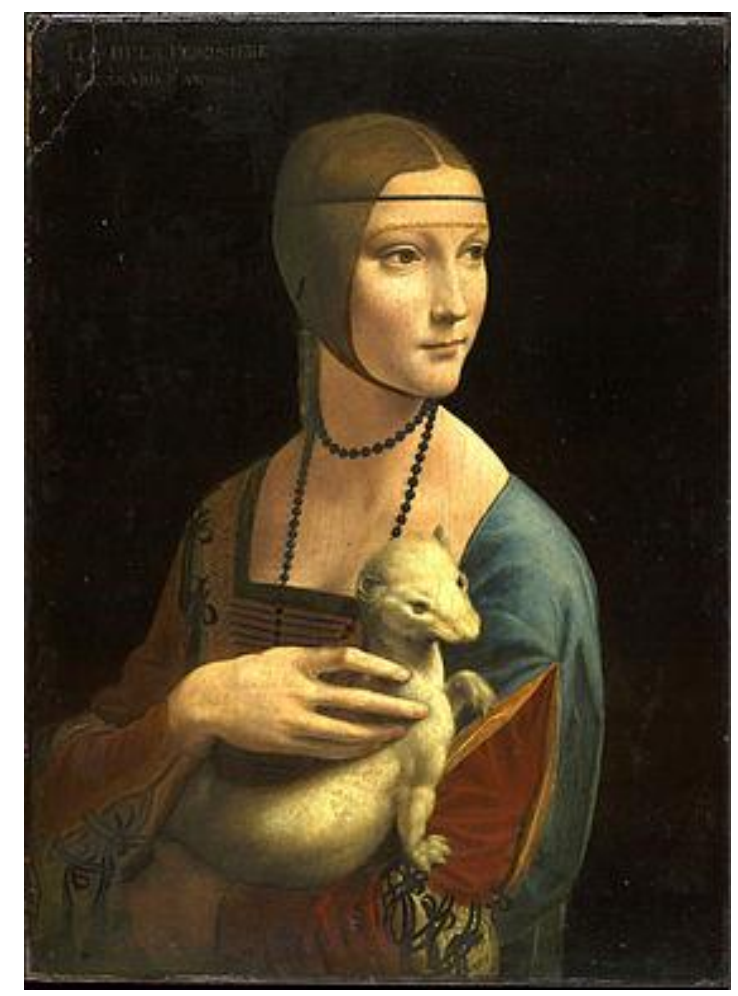

Figura 10 - VINCI, Leonardo da. Dama con l'ermellino. 1485-90. Óleo sobre tela. 54 x 40,3 cm. Museu Czartoryski, Cracóvia (Polônia).

\section{CONSIDERAÇÕES FINAIS}

Hoje vivemos em meio a uma profusão de rostos. É a era do Facebook e de revistas com títulos sintomáticos, como Caras (Figura 11). Rostos reconhecíveis, rostos irreconhecíveis (graças ao Photoshop) e rostos desconhecidos. Como num surto em que o psicótico tem seu mundo invadido por rostos, como visagens (não à toa, a palavra brasileira, interiorana, para dizer assombração deriva epistemologicamente de rosto), também no nosso 
mundo, chamado abusadamente de normal, há rostos por todos os lados. Rostos, em sua maioria jovens e sem marcas - sejam elas de experiências ou de tempo - nos outdoors, nas capas das revistas, nas telas de TV, nas embalagens de xampu e de pasta de dentes, nas caixas de brinquedos, de sapatos, nos pacotes de biscoitos. Ingerimos amido, açúcares, acidulantes, emulsificantes, espessantes e conservantes, mas nos alimentamos mesmo é de rostos. Rostos no lugar de vozes, rostos que vendem discos. Rostos que, se nos olham ou se fingem nos ignorar, o certo é que sempre nos convidam e convivem conosco em cada mínimo segundo das nossas vidas acordadas, nos nossos estados de delírio ou nos nossos sonhos.

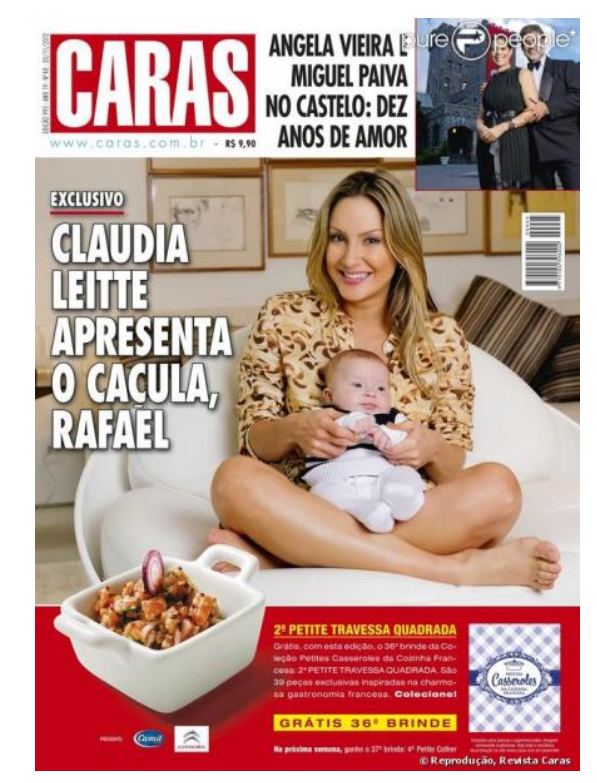

Figura 11 - Revista Caras. Editora Abril.

Atualmente, embora o gênero biográfico atinja com frequência o topo da lista dos Best Sellers, nossas biografias mais lidas são as revistas de fofoca em que os perfilados se expõem, voluntaria - abrindo suas casas, seus armários e seu coração - ou involuntariamente, presas apressadas sempre em fuga e acuados (sempre presas) dos paparazzi. Também os blogs pessoais, onde anônimos revelam o que não ousam contar em sua vida cotidiana, são autobiográficos. No twitter, a vida é fatiada, servida quente, sentida e escrita quase sem filtros de tempo, sem pausas para introspecção. É o desejo frenético, a febre de se ver publicizado, conectado. É a atualização da nossa permanente necessidade de vinculação, tão ligada à nossa sobrevivência física - necessidade que nos faz mamar, acariciar, beijar -, psíquica - de saber quem somos - e espiritual - vínculos de religação com uma dimensão que nos completa e que nos escapa - ainda que agora os elos sejam mais frágeis, dependentes da velocidade da 
conexão da internet, da bateria do celular ou da volatilidade dos nossos interlocutores, que rapidamente se interessam por outras experiências, por outros rostos. E o exercício de cura sui, de autorreflexão que sempre marcou a escrita autobiográfica, é desvirtuado para um projeto que prima pelo aqui e agora, pela invenção contemporânea do conceito de "tempo real".

E no meio de tanta exposição, nos perguntamos pelas dobras, pelas sombras, pelos não ditos. Acreditamos que escrevemos nossas vidas, acreditamos que autorizamos nossa imagem, que podemos tudo expor, tudo clarear. Mas as tecnologias dos aparelhos têm suas funções, que nos enquadram, que nos contornam e que nos pré-definem. Desprogramá-los é um exercício que requer tempo, paciência e (por que não dizer?) autorreflexão. E, se como disse Belting, a incerteza sobre nós mesmos gera a propensão que nos vejamos como outros e em forma de imagens, as imagens produzidas hoje, os rostos dos retratos que nos observam, são extremamente reveladores das nossas histórias de vida.

\section{REFERÊNCIAS}

BAITELLO, Norval. A era da iconofagia - ensaios sobre comunicação e cultura. São Paulo: Hacker, 2005.

BAYER, Raymond. História da Estética. Lisboa: Editorial Estampa, 1978.

BELTING, Hans. Antropología de la imagem. Buenos Aires: Katz Editores, 2007.

BELTING, Hans. Likeness and presence - a history of the image before the era of art.

Chicago: University Chicago Press, 1994.

BERMAN, M. Tudo o que é sólido se desmancha no ar. São Paulo: Companhia das Letras, 2007

BOURDIEU, Pierre. A ilusão biográfica. In: FERREIRA, Marieta de Moraes; AMADO, Janaína (orgs.). Usos e abusos da História Oral. 2. ed. Rio de Janeiro: Fundação Getúlio Vargas, 1998.

BURKE, Peter. A invenção da biografia e o individualismo renascentista. Estudos Históricos, 1997. Disponível em:

<http://virtualbib.fgv.br/ojs/index.php/reh/article/view/2038/1177>. Acesso em: 31 jan. 2011. 
Enciclopédia Itaú Cultural de Artes Visuais. Retrato. Disponível em:

$<$ http://www.itaucultural.org.br/aplicexternas/enciclopedia_ic/index.cfm?fuseaction=termos_t exto\&cd_verbete=364>. Acesso em: 31 jan. 2011.

FLUSSER, Vilém. A filosofia da Caixa Preta. Rio de Janeiro: Relume Dumará.

FLUSSER, Vilém. Bodenlos - uma autobiografia filosófica. São Paulo: Annablume, 2007.

FOUCAULT, M. As palavras e as coisas. Santos: Martins Fontes, 2007.

FOUCAULT, M. O que é um autor? Lisboa: Vega, 2009.

GALLE, H. et al. (orgs.) Em primeira pessoa - abordagens de uma teoria da autobiografia. São Paulo: Annablume, 2009.

GEBAUER, Günter e Christoph Wulf. Mimese na cultura. São Paulo: Annablume, 2004. KUNDERA, Milan. L’Art du Roman. Paris: Folio, 1986.

LEJEUNE, Philippe. Le pacte autobiographique. Paris: Éditions Du Seuil, 1996.

LEVI, Giovanni. Usos da biografia. In: FERREIRA, Marieta de Moraes; AMADO, Janaína (orgs.). Usos e abusos da História Oral. $2^{\text {a }}$ ed. Rio de Janeiro: Fundação Getúlio Vargas, 1998.

LOTMAN, Iuri. El retrato. In:___ La semiosfera III - Semiótica de las artes y de la cultura. Madrid: Ediciones Cátedra, 2000.

MARCONDES, Luiz Fernando. Dicionário de termos artísticos. Rio de Janeiro: Edições Pinakotheke, 1998.

POE, Edgar Allan. The oval portrait. Disponível em:

<http://books.eserver.org/fiction/poe/oval_portrait.html>. Acesso em: 27 set. 2009.

ROSENFELD, Anatol. Literatura e Personagem. In: CÂNDIDO, Antonio et al. A personagem de ficção. São Paulo, Perspectiva, 2005.

WILDE, Oscar. The Picture of Dorian Gray. In: WILDE, O. The Collected Works of Oscar Wilde. Great Britain: Wordsworth Library Collection, 2007. 
Doutora em Comunicação e Semiótica pela PUC/SP, Gabriela Reinaldo fez estágio posdoutoral no Departamento da Arte da Universidade de Cambridge, UK. É professora do Instituto de Cultura e Arte (ICA) da Universidade Federal do Ceará, onde coordena um grupo de pesquisa sobre Vilém Flusser e um grupo de pesquisa intitulado "As faces do rosto". Professora do Programa de Pós-graduação em Comunicação da UFC, seus interesses incluem Semiótica peirceana e Semiótica da Cultura, tradução intersemiótica, imagem, literatura e comunicação.

Esta obra está licenciada sob uma Licença Creative Commons. 